\title{
PENGARUH PEMBELAJARAN DARING TERHADAP HASIL BELAJAR SISWA DI SMPIT RAHMANIYAH FULLDAY SCHOOL
}

\section{THE EFFECT OF ONLINE LEARNING ON STUDENTS' LEARNING OUTCOMES AT SMPIT RAHMANIYAH FULLDAY SCHOOL}

\author{
Eva Destina1), Tjipto Djuhartono2), Dhani Harda Setiaji ${ }^{3),}$ \\ 1,2,3)Universitas Indraprasta PGRI

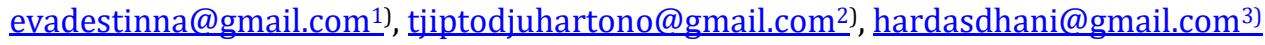

\begin{abstract}
Abstrak
Penelitian ini bertujuan untuk mengetahui seberapa besar pengaruh pembelajaran daring terhadap hasil belajar siswa di SMPIT Rahmaniyah Fullday school. Penelitan ini menggunakan metode kuantitatif. Penelitian ini merupakan penelitian deskriptif. Data primer diperoleh dengan menyebarkan kuesioner menggunakan google form secara online sedangkan data sekunder diperoleh dari nilai ulangan harian siswa kelas IX pada kompetensi dasar benua dan samudera. Populasi dalam penelitian ini adalah seluruh siswa kelas IX SMPIT Rahmaniyah Fullday school. Penelitian ini menggunakan sampel jenuh sebanyak 97 siswa. Teknik analisis data yang digunakan adalah koefisien regresi linear sederhana, analisis koefisien korelasi product moment, analisis koefisien determinasi dan pengujian uji t. Berdasarkan hasil perhitungan persamaan koefisien regresi linear sederhana bahwa $\hat{Y}=59,585+0,252 X$. Koefisien korelasi $r$ sebesar 0,142. Perhitungan koefisien determinasi diperoleh sebesar 2\% menunjukkan pembelajaran daring berpengaruh sangat rendah terhadap hasil belajar siswa dan sisanya 98\% ditentukan oleh faktor lain yang tidak dikaji dalam penelitian ini. Hasil perhitungan uji $t$ menunjukan t-hitung < t-tabel yaitu 1,399 < 1,985, maka dapat ditarik kesimpulan bahwa tidak terdapat pengaruh antara pembelajaran daring terhadap hasil belajar siswa.
\end{abstract}

Kata Kunci: pembelajaran, daring, hasil belajar siswa

\begin{abstract}
This study aims to determine how much influence online learning has on student learning outcomes at SMPIT Rahmaniyah Fullday school. This research uses quantitative methods. This research is descriptive research. Primary data was obtained by distributing questionnaires using an online google form while secondary data was obtained from the daily test scores of class IX students on the basic competencies of continents and oceans. The population in this study were all students of class IX SMPIT Rahmaniyah Fullday school. This study used a saturated sample of 97 students. The data analysis technique used is simple linear regression coefficient, product moment correlation coefficient analysis, coefficient of determination analysis and test testing. Based on the results of the calculation of the simple linear regression coefficient equation that $=59.585+0.252 X$. The correlation coefficient $r$ is 0.142. Calculation of the coefficient of determination obtained by $2 \%$ shows that online learning has a very low effect on student learning outcomes and the remaining $98 \%$ is determined by other factors not examined in this study. The results of the t-test calculation show that $t$-count $<t$-table is $1.399<1.985$, so it can be concluded that there is no influence between online learning on student learning outcomes.
\end{abstract}

Keywords: learning, online, student learning outcomes 
How to Cite: Destina, E., Djuhartono, T., \& Setiaji, D.H. (2021). Pengaruh pembelajaran daring terhadap hasil belajar siswa di SMPIT Rahmaniyah Fullday School. Al asma: Journal of Islamic Education, 3(2), 287-294.

\section{PENDAHULUAN}

Belajar merupakan suatu perubahan tingkah laku yang relatif permanen sebagai hasil dari pengalaman. Dalam lingkup sekolah, belajar merupakan suatu proses atau usaha yang siswa lakukan untuk mendapatkan perubahan sikap dan tingkah laku secara menyeluruh, sebagai hasil dari pengalaman siswa dalam interaksi dengan lingkungan sekitarnya (Andriani \& Rasto, 2019). Umumnya kegiatan belajar dilakukan secara tatap muka di sekolah oleh guru. Namun, saat situasi pandemi Covid-19 tidak memungkinkan jika siswa harus melaksanakan kegiatan belajar mengajar di sekolah. Meski demikian belajar mengajar harus tetap berlangsung dengan media daring untuk mengetahui sejauh mana hasil belajar siswa.

Pada prinsipnya, pengungkapan hasil belajar ideal meliputi segenap ranah psikologi yang berubah sebagai akibat pengalaman dan proses belajar siswa. Namun demikian, pengungkapan perubahan tingkah laku seluruh ranah itu, khususnya ranah rasa murid sangat sulit, hal ini disebabkan perubahan hasil belajar itu ada yang bersifat intangible (tidak dapat diraba) (Endaryono \& Djuhartono, 2021). Menurut Asikin dan Interdiana (2019) faktor-faktor yang mempengaruhi hasil belajar siswa ada dua, yaitu faktor yang berasal dari dalam (internal) dan faktor yang berasal dari luar (eksternal).

Faktor internal yang mempengaruhi hasil belajar siswa yang berasal dari dalam diri siswa itu sendiri. Dengan adanya semangat belajar yang tinggi akan meningkatkan kemampuan siswa untuk menguasai pelajaran dan mendapatkan hasil belajar yang memuaskan. Semangat belajar yang terus dipertahankan, akan terbentuk kebiasaan belajar yang baik. Faktor internal dibagi menjadi dua, diantaranya kondisi psikologis dam kondisi fisiologi (Hakim, 2011). Kondisi psikologi menyangkut kecerdasan, minat, bakat, motivasi, perhatian, kematangan, kesiapan dan sikap. Kecerdasan tidak hanya berkaitan dengan kualitas otak saja, tetapi organ-organ tubuh lain. Kecerdasan mencakup kecakapan yang terdiri dari tiga jenis yaitu kecakapan untuk menghadapi dan menyesuaikan ke dalam situasi yang baru dengan cepat dan efektif, menggunakan konsep yang abstrak secara efektif, serta mengetahui relasi dan mempelajarinya dengan cepat. Kecerdasan yang di landasi dengan minat serta bakat akan memotivasi siswa untuk mempersiapkan diri dengan menaruh perhatian pada kegiatan belajar sehingga tercapai kematangan berfikir. Kondisi fisiologis menyangkut kondisi fisik dan kondisi panca indra. Kondisi fisik memiliki pengaruh besar terhadap kemampuan belajar. Orang yang dalam keadaan segar jasmaninya akan berbeda belajarnya dengan orang yang berada dalam keadaan kelelahan, sedangkan kondisi panca indra juga berpengaruh terhadap keberhasilan belajar. Seseorang yang memiliki kekurangan fisik harus diberikan semangat khusus dengan alat bantu khusus dan belajar di sekolah yang khusus pula.

Faktor eksternal merupakan faktor yang berasal dari luar. Dalam hal ini bisa disebutkan orang lain bisa mendorong siswa untuk belajar lebih giat. Faktor eksternal meliputi instrumental input dan enviromental input (Ramadhan, Wiyono, Adlika, Fiemansyah, \& Budiman., 2021). Faktor instrumental input menyangkut bagaimana kualitas guru dalam menyampaikan pelajaran, kurikulum yang digunakan di sekolah, 
sarana dan prasarana yang tersedia untuk menunjang kegiatan pembelajaran, rancangan program pengajaran dan program bimbingan yang dirancang sekolah.

Pada masa pandemi seperti saat ini, pemerintah khususnya Kemendikbud berupaya keras agar siswa tetap bisa menerima pelajaran dengan baik. Perkembangan teknologi yang ada saat ini diharapkan dapat menjadi penunjang yang baik sebagai pengganti tatap muka dalam penyampaian pelajaran dari guru kepada siswa.

Dalam menghadapi siswa paling sedikit ada tiga aspek yang membedakan anak didik yang satu dengan yang lainnya; yaitu aspek intelektual, psikologis, dan biologis (Djamarah \& Zain, 2010). Ketiga aspek tersebut menjadi akar permasalahan yang melahirkan variasi sikap dan tingkah laku anak didik di sekolah. Hal itu juga menjadi tugas cukup berat bagi guru dalam mengelola kelas dengan baik. Keluhan-keluhan sering terlontar hanya karena masalah sukarnya mengelola kelas. Akibat kegagalan guru mengelola kelas, tujuan pengajaran pun sukar untuk dicapai (Endaryono \& Djuhartono, 2021).

Pembelajaran daring adalah pembelajaran yang mampu mempertemukan siswa dan guru untuk melaksanakan interaksi pembelajaran dengan bantuan internet (Sadikin \& Hamidah, 2020). Menurut Aulia Puspita Sari (2020) terdapat masalah yang muncul dalam penggunaan sistem belajar daring yang dialami siswa maupun guru, sebagai contoh materi yang belum selesai disampaikan oleh guru, kemudian guru tidak meneruskannya melainkan mengganti dengan tugas lainnya. Hal tersebut menjadi beban bagi siswa karena tugas yang diberikan oleh guru lebih banyak daripada materi yang dijelaskan. Permasalahan lainnya yaitu kendala sinyal yang tidak stabil mengakibatkan akses informasi menjadi terganggu, sehingga siswa tertinggal dalam menangkap informasi yang bisa berdampak pada keterlambatan dalam pengumpulan tugas yang diberikan oleh guru (Sari \& Wisroni, 2020).

SMPIT Rahmaniyah Fullday school adalah salah satu sekolah menengah pertama di kota Depok yang memiliki fasilitas belajar lengkap dengan ruang kelas, laboratorium komputer, perpustakaan, ruang studio, masjid dan perpustakaan dimana seluruhnya di lengkapi dengan AC dan WIFI sekolah. Pada ruangan tertentu terdapat LCD projector, speaker dan CCTV. Pembelajaran merupakan sebuah proses terjadinya interaksi antara siswa dan guru, dengan menggunakan bahan ajar, metode dalam menyampaikan pelajaran, strategi pembelajaran, dan sumber belajar lain dalam sebuah lingkungan belajar (Pane \& Dasopang, 2017). Berdasarkan penelitian yang telah dilakukan, pembelajaran yang dilakukan di SMPIT Rahmaniyah Fullday school pada masa pandemi memakai metode pembelajaran daring. Pembelajaran daring SMPIT Rahmaniyah Fullday school menggunakan media zoom meeting, whatsaap grup, dan google classroom. Media tersebut bergantian digunakan oleh guru untuk menyampaikan pelajaran kepada siswa. Menurut Imania (2019) pembelajaran daring merupakan bentuk penyampaian pembelajaran konvensional yang dituangkan pada format digital melalui internet. Pembelajaran daring dianggap menjadi satu-satunya media penyampai materi antara guru dan siswa, dalam masa darurat pandemi (Hafiz, Desniarti, \& Anisa, 2020). Proses pengajaran adalah kegiatan belajar siswa dalam mencapai suatu tujuan pengajaran. Tujuan pembelajaran dapat tercapai apabila siswa berusaha secara aktif untuk mencapainya. Keaktifan siswa tidak hanya dituntut dari segi fisik, tetapi juga dari segi psikis. Jika hanya dari segi fisik saja yang aktif dan mentalnya kurang aktif, maka dapat disebut tujuan dari pembelajaran 
ini belum tercapai. Hal ini sama saja dengan siswa tidak belajar, karena siswa tidak merasakan perubahan dalam dirinya (Pane \& Dasopang, 2017). Pada praktik pelaksanaanya pembelajaran daring sangat memerlukan perangkat penunjang seperti smartphone, laptop atau komputer, dan tablet yang bisa digunakan untuk mengakses informasi kapanpun dan dimanapun (Rigianti, 2020).

Siswa SMPIT Rahmaniyah Fullday school mayoritas sudah memiliki alat komunikasi pribadi seperti smartphone dan laptop atau komputer. Sehingga memudahkan mereka untuk tetap belajar meskipun tidak bertatap muka secara langsung. Peneliti mengambil penelitian di SMPIT Rahmaniyah Fullday school karena sebagian besar siswa kelas IX memiliki rumah di wilayah yang mudah terjangkau sinyal internet dan memiliki fasilitas yang mencukupi untuk melaksanakan kegiatan pembelajaran daring, sehingga pada akhirnya bisa diambil keputusan apakah terdapat pengaruh antara pembelajaran daring terhadap hasil belajar siswa.

\section{METODE PENELITIAN}

Penelitian ini menggunakan survey dengan metode kuantitatif deskriptif. Data yang akan diperoleh berupa angka dan akan dianalisis lebih lanjut dalam analisis data. Menurut Sugiyono (2012) metode survey digunakan untuk mendapatkan data dari tempat tertentu yang alamiah (bukan buatan), tetapi peneliti melakukan perlakuan dengan pengumpulan data, misalnya dengan mengedarkan kuesioner, test, wawancara terstruktur dan sebagainya. Dengan menggunakan metode survey dapat diketahui apakah bahwa terdapat hubungan antara variabel yang diteliti atau tidak, sehingga menghasilkan kesimpulan yang akan memperjelas gambaran mengenai objek yang diteliti. Dalam penelitian ini ada dua jenis variabel yang akan di teliti, yaitu variabel independen dan variabel dependen.

Teknik pengumpulan data yang dipakai dalam penelitian ini memakai dua data penelitian, yaitu penelitian primer dan sekunder. Data primer dalam penelitian ini didapatkan dengan cara menyebarkan kuesioner secara online. Populasi penelitian ini adalah semua siswa kelas IX di SMPIT Rahmaniyah Fullday school yang berjumlah 97 siswa. Sumber data diperoleh dari siswa kelas IX SMPIT Rahmaniyah Fullday school sebagai populasi dan sampel untuk variabel $\mathrm{X}$ dan nilai ulangan harian mata pelajaran IPS kelas IX siswa SMPIT Rahmaniyah Fullday school sebagai variabel Y.

Sampel diambil dengan metode sampel jenuh dengan memakai seluruh populasi yang ada. Jenis kuesioner yang dipakai ialah kuesioner tertutup. Kuesioner tersebut berisi item pernyataan terkait persiapan siswa, fasilitas belajar daring, motivasi belajar, pemahaman materi, dan kendala siswa yang akan ditandai oleh responden dengan cara memilih jawaban di kolom telah yang tersedia. Adapun data sekunder digunakan untuk pengambilan data dokumentasi yang dibutuhkan peneliti dari sekolah. Data dokumentasi yang digunakan pada penelitian ini adalah nilai ulangan harian semester 1 kelas IX mata pelajaran IPS kompetensi dasar benua dan samudera. Jawaban kuesioner dianggap valid jika nilainya dari $r>0,1996$. Sedangkan uji reliabilitas adalah suatu pengukuran keandalan konsistensi internal dengan mencari koefisien alpha $(\alpha)$, Jika alpha Cronbach $>0,5$, maka penelitian dapat diandalkan untuk digunakan dalam proses analisis data. Data penelitian dianalisis memakai analisis butir soal dengan bantuan SPSS versi 16 lalu menggunakan uji 
validitas dan uji reliabilitas, kemudian dianalisis dengan bantuan SPSS versi 16 menggunakan uji linier sederhana.

\section{HASIL DAN PEMBAHASAN}

Jumlah responden dalam penelitian ini adalah 97 siswa, diantaranya 52 siswa berjenis kelamin laki-laki dan 45 siswa lainnya berjenis kelamin perempuan. Siswa dan siswi kelas IX tersebar dalam dua kelas perempuan (kelas Maryam dan kelas Rufaidah) serta dua kelas laki-laki (kelas Ibnu Haitam dan Ibnu Al Baithar). Berdasarkan nilai ulangan harian, diperoleh gambaran hasil belajar IPS yang digambarkan pada gambar 1, dapat diketahui bahwa jumlah siswa yang nilainya tergolong pada kategori tinggi sebanyak 42 siswa (43,29\%), kategori nilai sedang sebanyak 48 siswa $(49,48 \%)$ dan $7,2 \%$ siswa yang berada pada kategori rendah.

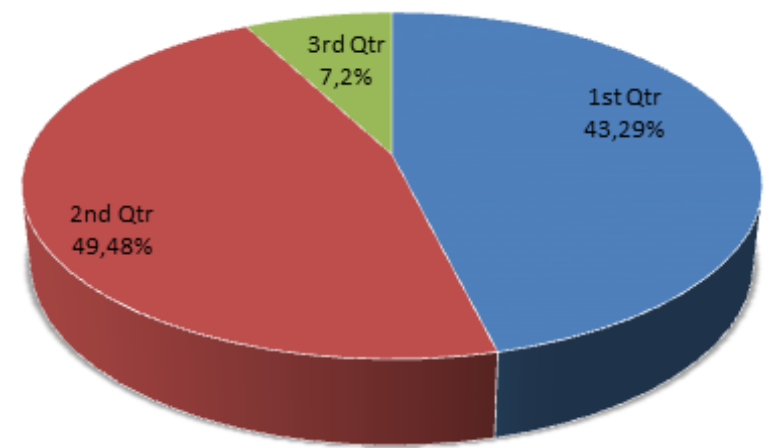

Gambar 1. Hasil Belajar yang diperoleh Siswa Kelas IX

Beragam respon siswa dalam menjawab pernyataan yang diajukan peneliti. Mayoritas siswa kelas IX SMPIT Rahmaniyah fullday school sudah melakukan persiapan sebelum meraka melaksanakan kegiatan belajar mengajar melalui daring. Sebagian besar siswa memiliki telepon pintar dan memiliki fasilitas internet yang bagus, sehingga sangat meminimalisir kemungkinan gangguan yang akan terjadi saat pembelajaran daring berlangsung. Dalam melaksanakan pembelajaran daring, siswa sebagian mengaku bahwa semangatnya dalam belajar kadang berkurang sehingga mereka tidak yakin akan hasil belajar yang baik bisa meraka capai.

Tabel 1. Uji Regresi

\begin{tabular}{cccc}
\hline & Model & B & Std. Error \\
\hline \multirow{2}{*}{1} & (Constant) & 59.585 & 15.349 \\
& $\mathrm{X}$ & .252 & .180 \\
\hline
\end{tabular}

Dari tabel 1, persamaan koefisien regresi linear sederhana yang terbentuk dari perhitungan diatas adalah $\mathrm{Y}=59,585+0,252 \mathrm{X}$. Dari persamaan regresi tersebut, maka dapat disimpulkan bahwa apabila hasil belajar siswa sebesar a atau 59,585 sedangkan pengaruh pembelajaran daring terhadap hasil belajar siswa sebesar $b$ atau 0,252 sehingga jika pembelajaran daring ditingkatkan maka hasil belajar siswa meningkat sebesar b atau 0,252 . 
Tabel 2. Uji Kolerasi

\begin{tabular}{cc}
\hline Model & $\mathbf{R}$ \\
\hline 1 & $.142^{\mathrm{a}}$ \\
\hline
\end{tabular}

Berdasarkan tabel 2, diperoleh nilai koefisien kolerasi (R) sebesar 0,142 atau $14,2 \%$ yang berarti tingkat hubungan variabel pembelajaran daring dan hasil belajar siswa adalah sangat rendah dikarenakan berada dalam interval $(0,0-0,20)$. Hal di atas berdasarkan pedoman interpretasi koefisien kolerasi sebagai berikut:

Tabel 3. Uji Koefisien Determinasi

\begin{tabular}{cc}
\hline Model & R Square \\
\hline 1 & .020
\end{tabular}

Nilai koefisien determinasi $\left(\mathrm{R}^{2}\right)$ sebesar 0,020. Hal ini berarti variabel pembelajaran daring dapat menjelaskan pengaruhnya terhadap hasil belajar siswa sebesar $2 \%$, sedangkan sisanya yaitu sebesar $100 \%-2 \%=98 \%$ dijelaskan oleh faktor-faktor lain di luar model penelitian. Faktor-faktor lain ini berupa kecerdasan siswa, minat, bakat, kesiapan, motivasi, kurikulum, sarana dan fasilitas belajar dan lingkungan sosial.

Tabel 4. Uji t

\begin{tabular}{cccc}
\hline Model & $\mathbf{T}$ & Sig. & Keterangan \\
\hline (Constant) & 3.882 & .000 & Ha ditolak \\
$\mathrm{X}$ & 1.399 & .165 & \\
\hline
\end{tabular}

Tabel 4 merupakan hasil olah uji t dengan menggunakan SPSS. Jika nilai t-hitung > t-tabel maka hasilnya Ho ditolak atau berarti variabel bebas berpengaruh secara parsial terhadap variabel terikat. Jika nilai t-hitung<t-tabel maka hasilnya Ho diterima atau berarti variabel bebas tidak berpengaruh secara persial terhadap variabel terikat. Jika nilai signifikansi lebih besar dari 0,05 maka Ho diterima, berarti memiliki pengaruh yang tidak signifikan. Sedangkan jika tingkat signifikansi lebih kecil dari 0,05 maka Ho di tolak berarti memiliki pengaruh yang signifikan. Berdasarkan tabel diatas, nilai thitung variabel pembelajaran daring 1,399 < 1,985 dan nilai signifikansi 0,165 > 0,05 maka Ho diterima dan dapat di simpulkan jika pembelajaran daring secara parsial tidak berpengaruh dan tidak signifikan terhadap variabel hasil belajar siswa. Berdasarkan hasil analisis data, diperoleh t-hitung<t-tabel $(1,399<1,985)$. Hal tersebut menunjukkan bahwa pembelajaran daring tidak mempengaruhi hasil belajar siswa di SMPIT Rahmaniyah Fullday school.

Tidak adanya pengaruh pembelajaran daring terhadap hasil belajar siswa di SMPIT Rahmaniyah Fullday school memiliki artian bahwa siswa masih tetap dapat memperoleh hasil belajar yang baik meskipun tidak melaksanakan pembelajaran secara tatap muka di sekolah. Siswa akan tetap bisa merasa nyaman dan berkonsentrasi penuh apabila lingkungan belajar kondusif dan fasilitas belajar sudah terpenuhi. Selain itu kurikulum dan inovasi guru dalam menyampaikan pelajaran untuk mempertahankan semangat siswa dalam belajar, sehingga hasil yang diperoleh pun semakin baik.

Hasil penelitian ini didukung teori yang dikemukakan oleh Asikin dan Interdiana (2019) bahwa faktor yang mempengaruhi hasil belajar terdiri dari faktor internal dan eksternal. Faktor internal meliputi kondisi psikologis siswa berupa kecakapan untuk 
menghadapi dan menyesuaikan ke dalam situasi yang baru dengan cepat dan efektif dan kondisi fisiologis yang menyangkut panca indera siswa. Faktor eksternal meliputi faktor instrumental yang menyangkut bagaimana kualitas guru dalam menyampaikan pelajaran, kurikulum yang digunakan di sekolah, sarana dan prasarana yang tersedia untuk menunjang kegiatan pembelajaran dan Faktor enviromental input yang meliputi lingkungan alam dan lingkungan sosial.

Selain itu penelitian ini sejalan dengan penelitian terdahulu yang dilakukan oleh Sholikin (2021) bahwa ada pengaruh antara pembelajaran daring terhadap hasil belajar siswa dengan nilai $\mathrm{R}$ Square sebesar 0,065 atau sebesar 6,5\%, sementara 93,5\% dipengaruhi oleh faktor lain, baik faktor lingkungan, faktor kondisi fisiologis maupun faktor kondisi psikologis siswa yang sudah dipengaruhi oleh pembelajaran daring itu sendiri.

\section{SIMPULAN}

Berdasarkan hasil penelitian dan pembahasan diperoleh bahwa terdapat pengaruh hubungan yang sangat rendah antara variabel $X$ (pembelajaran daring) dengan variabel $Y$ (hasil belajar siswa SMPIT Rahmaniyah Fullday school). Pembelajaran yang dilakukan oleh siswa baik melalui daring maupun tatap muka di sekolah disimpulkan tidak ada perbedaan, karena siswa masih tetap bisa mengikuti pelajaran dengan baik. Hasil belajar siswa tidak dipengaruhi oleh pembelajaran daring, melainkan faktor lain seperti faktor lingkungan, faktor kondisi fisiologis maupun faktor kondisi psikologis siswa.

\section{DAFTAR PUSTAKA}

Andriani, R., \& Rasto. (2019). Motivasi belajar sebagai determinan hasil belajar siswa. Jurnal Pendidikan Manajemen Perkantoran, 4(1), 80-86. https://doi.org/10.17509/jpm.v4i1.14958

Asikin, M. I., \& Interdiana. (2019). Strategi belajar dan pembelajaran. Unindra Press.

Djamarah, S. ., \& Zain, A. (2010). Strategi belajar mengajar. Jakarta: Rineka Cipta.

Endaryono, B. T., \& Djuhartono, T. (2021). Pengaruh kinerja guru bidang studi terhadap prestasi belajar siswa kelas X SMK Bisnis dan Teknologi Bekasi. Jurnal Dirosah Islamiyah, 3(1), 78-87. https://doi.org/10.47467/jdi.v3i1.306

Hafiz, M., Desniarti, \& Anisa, Y. (2020). Pembelajaran daring yang dihadapi guru sekolah menengah atas. JIP: Jurnal Ilmu Pendidikan, 1(2), 103-106. Retrived From https://jurnal-lp2m.umnaw.ac.id/index.php/JIP/article/view/598

Hakim, T. (2011). Belajar secara efektif. Jakarta: Puspa Swara.

Imania, K. A. N. (2019). Rancangan pengembangan instrumen penilaian pembelajaran berbasis daring. Jurnal PETIK, 5(1), 31-47. https://doi.org/10.31980/jpetik.v5i1.445

Pane, A., \& Dasopang, M. . (2017). Belajar dan pembelajaran. FITRAH Jurnal Kajian IlmuIlmu Keislaman, 1(1), 33-352. https://doi.org/10.24952/fitrah.v3i2.945

Ramadhan, I., Wiyono, H., Adlika, N. M., Fiemansyah, H., \& Budiman, J. (2021). Kiat sukses ptk (langkah-langkah, instrumen dan contoh). Penerbit Lakeisha.

Rigianti, H. A. (2020). Kendala pembelajaran daring guru sekolah dasar di kabupaten banjarnegara.

Elementary

School,

$7(2)$,

297-302. 
https://doi.org/10.31316/esjurnal.v7i2.768

Sadikin, A., \& Hamidah, A. (2020). Pembelajaran daring di tengah wabah covid-19. BIODIK: Jurnal Ilmiah Pendidikan Biologi, 6(1), 214-224. https://doi.org/10.22437/bio.v6i2.9759

Sari, A. P. (2020). Peran orangtua dalam pembelajaran daring pada siswa kelas 1 di SD Negeri 1 Taman Asri. IAIN Metro.

Sari, N. ., \& Wisroni. (2020). The urgency of parental guidance for youth education in the belajar dari rumah (BDR) era. SPEKTRUM Jurnal Pendidikan Luar Sekolah (PLS), 1(3), 310-321. https://doi.org/10.24036/spektrumpls.v8i3.109565

Sholikin, R. (2021). Pengaruh pembelajaran daring terhadap hasil belajar siswa kelas $x$ pada mata pelajaran pendidikan agama islam di SMA Negeri 1 Sambit Ponorogo 2020/2021. IAIN Ponorogo.

Sugiyono. (2012). Memahami penelitian kualitatif. Bandung: Alfabeta. 